\title{
An Ontology Engineering Approach to User Profiling for Virtual Tours of Museums and Galleries
}

\author{
W. A. Eardley, D. E. Ashe, and B. D. Fletcher
}

\begin{abstract}
This paper describes a study of the development of a hierarchical ontology for producing and maintaining personalized profiles to improve the experience of visitors to virtual art galleries and museums. The paper begins by describing some of the features of virtual exhibitions and offers examples of virtual tours that the reader may wish to examine in more detail. The paper then discusses the ontology engineering (OE) approach and domain modelling languages (e.g. KACTUS, SENSUS and METHONTOLOGY). It then follows a basic $O E$ approach to define classes for a cultural heritage virtual tour and to produce a Visitor Profile Ontology that is hierarchical and has static and dynamic elements. It concludes by suggesting ways in which the ontology may be automated to provide a richer, more immersive personalized visitor experience.
\end{abstract}

Index Terms-Ontology engineering, virtual tour, personalization, profiling, domain modelling.

\section{INTRODUCTION}

Virtual exhibitions and tours of art galleries and museums, whether web-based or merging the real world with the virtual one through using augmented reality [1] are becoming increasingly popular. Museums are moving away from conserving and displaying artefacts to focusing on an educational and entertaining social experience for the 'visitor' [2]. One significant fact about the prevalence of such online virtual tours is that in addition to entertaining the user they seek to impart knowledge and to provide a valid educational experience [3]. A trip to a museum or gallery has long been in the curriculum of most arts or science subjects at school and university. Virtual environments now open up more educational options and opportunities to acquire knowledge. Users (students, researchers and aficionados) can make 'visits' to museums and galleries that would not be possible in real life due to the constraints of time, cost and mobility.

Although physically moving around a gallery or museum has the advantage of being aesthetically appealing [4] the layout or display space of the exhibits may be limited or curtailed by the museum's curators, due to the restoration or conservation of exhibits or the museum's actual physical space, depth and size [5].

Some exhibits may even be too precious to put on public display. An online three-dimensional (3D) virtual museum, on the other hand, helps to promote the museum's collections,

Manuscript received March 15, 2016; revised June 1, 2016.

W. A. Eardley and B. D. Fletcher are with the Faculty of Computing Engineering and Sciences at Staffordshire University, U.K. (e-mail: w.a.eardley@staffs.ac.uk, b.d.fletcher@staffs.ac.uk).

D. E. Ashe is with the Faculty of Arts and Creative Technologies at Staffordshire University, U.K. (e-mail: denise.ashe@ research.staffs.ac.uk). to extend the longevity of temporary or special exhibitions, encourages physical visits and provides non-stop remote access to a worldwide audience. In some virtual museums or galleries, visitors are able to follow a guided tour using interactive maps and examine virtual replicas of great masterpieces and valuable artefacts. Some even create their own virtual tour by navigating freely around the collection [6]. In addition, the visitor may be provided with a richer experience in an immersive environment, which is engaging, thought provoking and informative. In a real gallery or museum, the visitor is left with rich personal impressions of an emotional and intellectual experience, creating a memory, which may be evoked later [7]. It is important to replicate these emotions if the 'full value' of a virtual visit is to be obtained. This paper examines some types of gallery or museum online presence and suggests some ways in which the experience can be improved through ontology engineering (OE) and personalization.

The website 'Virtualfreesites' [8] currently includes over 300 sites that are described as 'Museums, Exhibits, Points of Special Interest and Real-Time Journeys' and offers 'online guided tours on the Web'. The sites display a range of material from 'flat' text and images providing information about the museum or gallery and the exhibition and artefact to the type of rich, immersive experience described above. These sites use interactive multi-media featuring personalized content with sound and videos to 'immerse' the visitor. Two types of immersive experience are recognized, mental and physical. Mental immersion occurs when the visitor's imagination is being pushed and defied, while physical immersion is achieved through the 'realism' of the virtual interface [5]. On the other hand, some virtual tours are in effect simply a way of introducing the features and attractions of the museum or gallery and preparing the user for an actual visit, while others use a mobile application to guide the visitor around the 'real' exhibition [9].

Popular virtual tours include conventional museums and galleries such as the Smithsonian Natural History Museum in Washington, D.C. [10], the Louvre Museum in Paris [11], and the Oxford University Museum of Natural History [12]. In addition, there are sites that feature exhibitions that are not site-specific but are grouped according to specific themes, such as the European Virtual Museum [13], which combines a collection of items from various museums in Europe into a series of virtual exhibitions as 3D images. This in effect creates the potential for a 'real' tour of a virtual museum, rather than a virtual tour of a 'real' museum. Other museums or galleries offer virtual experiences that do not seek to replicate a tour, but which display exhibits that meet the user's preference of theme or type, such as the Rijksmuseum in 
Amsterdam [14].

\section{ONTOLOGY ENGINEERING}

Ontologies have been used for some time in the fields of computer and information science as formal naming conventions and definitions of the properties, types and relationships between the entities that exist within a particular domain or 'universe of discourse' [15]. As such they have assisted in the categorization and definition (and therefore the understanding) of the things in which individuals and groups are interested and that influence their activities and dialogues [16]. As a comparison Neches [17] states that an ontology 'defines the basic terms and relations comprising the vocabulary of a topic area as well as the rules for combining terms and relations to define extensions to the vocabulary'. This stresses the procedural aspect of an ontology as being equal to the lexical aspect. Since their development as a philosophical concept in the mid-1990s, ontologies have become important in academic areas such as knowledge representation, artificial intelligence and the semantic web. An ontology for an application such as a gallery or museum will contain an upper or top-level ontology, which describes very general concepts that are similar across all domains of knowledge and a domain ontology that contains attributes that are relevant to the domain of interest (e.g. archeology or fine art).

Studer [18] makes it clear that the terms in an ontology can be explicit (i.e. formally defined) or implicit if their intended meaning can be implied [19]. Hendler [20] refers to the 'semantic interconnections' and 'rules of inference and logic' in an ontology. This has important implications for the way in which knowledge is represented and for the language that is used to implement the ontology. Signore [21] classifies these domain ontology modelling methods as:

- Highly informal - described in natural language, which is understandable to humans but may not be machine readable;

- Semi-informal - represented by a restricted form of natural language e.g. Structured English or Gellish [22];

- Semi-formal - written in a specialised artificial language such as OWL [23];

- Completely formal-specified by rigorously defined terms with formal semantics, theorem proofs etc. [24].

Domain ontologies therefore constitute the 'language' for modelling domains and their processes and actors. They have been applied in library and archive management (e.g. the Dublin Core Schema [25]), galleries and museums (e.g. CIDOC CRM [26]) and personal relationships (e.g. FOAF [27]). OE is a way of constructing an ontology that follows a recognized iterative software lifecycle or engineering approach. Some examples of OE methodologies include:

- KACTUS [28], which follows a 'bottom-up' strategy and works by a process of abstraction, becoming more general at the higher levels and therefore capable of being adapted for other applications than those for which it was developed;

- SENSUS [29], which by contrast is a top-down approach for deriving domain specific ontologies from large sets of data. SENSUS uses a tree structure to 'fill in' nodes until the ontology is complete. The approach promotes knowledge sharing, as the same root ontology can be developed into ontologies for different domains;

- Methontology, which is claimed [30] to be able to acquire the knowledge of the domain area and represent it by the creation of a vocabulary list or glossary. Developed using criteria set by an IEEE standard, it uses an iterative approach that includes three sets of activities: management (e.g. control, quality assurance and scheduling), development activities (e.g. specification, conceptualization, formalization) and support (e.g. knowledge acquisition, integration and evaluation). The life cycle includes the stages through which the ontology passes over time and the links it has with other ontologies.

The choice of an OE methodology for a gallery or museum project can be difficult for the following reasons [31]. Firstly, most OE methodologies are not mature and operable when compared to software engineering and knowledge engineering methodologies of the same generation. Secondly, many key software development activities are not included in OE lifecycles. Finally, OE methodologies are not unified and each applies its own standards and approach. In any case, once an OE methodology is applied, the ontology can be developed.

Generally, a gallery or museum application will have a core ontology (e.g. CIDOC CRM) and core metadata (e.g. Dublin Core). In such cases, the metadata will be in a highly informal or semi-informal language and the core ontology will be semi-formal or completely formal [21]. CIDOC is an object-oriented $(\mathrm{OO})$ reference model that has an ontology of over 80 classes and over 130 unique properties, and 'which describes in a formal language concepts and relations relevant to the documentation of cultural heritage' [21]. The metadata can therefore be understood by humans, while the core ontology can be processed by automated tools, reasoning on the links between the user's interests and preferences and the exhibits and the information about them. The adjective 'semantic' in this context implies that the semantic web can be used to import the data from any knowledge representation system and, by expressing the data and reasoning rules, to export the results onto the World Wide Web [21].

\section{Personalized Virtual TOURS}

The main advantage of a virtual exhibition is the opportunity to understand the visitor's preferences (e.g. in terms of aesthetic themes and exhibits), his or her level of knowledge (e.g. novice or expert) and to 'personalize' the learning experience to the individual through interactive user modelling [32]. The aim of the long-running CHIP project at the Rijksmuseum is to:

'...bridge the vocabulary gap and provide a user-driven approach for eliciting user's (sic) preferences and characteristics, and recommend known/new information from the collection in a coherent and comprehensive way'.

(Wang, Aroyo, Stash and Rutledge. [32], P. 2).

In other words, to find out what the visitor knows (i.e. the 
knowledge of the domain area), the visitor's interests (i.e. the reason for 'visiting' the exhibition) and understanding (i.e. the level of expertise) and to use this information to provide and control access to exhibits that satisfy the user's preferences. Research into personalization has been carried out for some time in the fields of artificial intelligence (AI), data retrieval and data mining [33]. It is recognized that online tours and exhibitions enable opportunities for providing a deeper experience to the virtual visitor by offering personalized services based on user profiling [34]. Many museums feature personalized tours and additional collections in their online presence. For instance, the CHIP project uses semantic web technology to provide personalized access to digital and real gallery and museum collections [35]. Cultural heritage personalization assists visitors in the selection and filtering of artworks and artefacts [34] to avoid information overload [36]. The amount of digital data that is presented online and the number and diversity of online visitors makes some form of adaptation imperative.
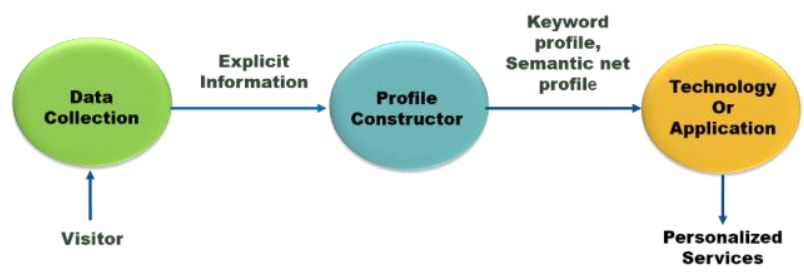

Fig. 1. Overview of visitor-profile-based personalization. (Based on and adapted from Gauch, Speratta, Chandramouli and Micarelli [33]).

Pechenizkiy and Calders [34] categorize adaptive systems into customized (adaptable) and personalized (adaptive). Customization is user-driven adaptation and refers to the ability of the visitor explicitly to change the visitor profile and to tailor the presentation of the content. Personalization is system-driven adaptation that aims to achieve the same ends by user profiling [6]. According to Schiaffimo and Amandi [37], a basic user profile is vital information about an individual person. In the context of a museum, a profile is shown in overview form in Fig. 1.

In the data gathering phase of profiling, raw data is collected about the visitor either explicitly by direct human intervention or implicitly by automatically monitoring the user's behavior and actions in the museum [33], [37]. In the profile construction phase, both types of data combine to form information that is input to profile constructor software. The visitor's profile is therefore a record of his or her unique characteristics such as:

- Socio-demographic characteristics [38] - age, gender, occupation, education, impairments etc.;

- 'Museological' characteristics [38] - purpose of visit, interest in museum topics, preferences of subject, prior knowledge, level of engagement with the topic, etc.;

- Visit type - individual types (e.g. casual, cursory or study) [39], group types (e.g. families, tourists or school parties etc.) [40], frequency of visit, duration of visit;

- Psychological factors - memory, learning style [41] cognitive style [42], visiting style [43] etc.

This is then stored, either as a keyword profile, a semantic net profile or a concept profile. By applying the profile to a technology solution or application, such as a recommender system [33] a personalized service can then be provided to the visitor to improve his or her experience [44]. If done effectively this can turn a monologue ('the museum talking to the visitors') into a dialogue ('the museum talking with the visitors'). In this way the upper ontology (i.e. the things in the domain that all users are interested in or affected by) is augmented by an individual user profile (i.e. the user's specific characteristics).

TABLE I: VISITOR PROFILE ONTOLOGY

\begin{tabular}{|c|c|c|}
\hline Class_name & Class_description & Example_values \\
\hline Visitor & Person visiting gallery or museum. & "name", "address", "contact details",. \\
\hline Visitor_profile & Visitor's basic demographic details & $\begin{array}{l}\text { "age", "gender", “education", "occupation", "first } \\
\text { language", "impairments" [38]. }\end{array}$ \\
\hline Visit & Place of the current visit & $\begin{array}{l}\text { "gallery reference", "museum reference", "gallery } \\
\text { location", "museum location," }\end{array}$ \\
\hline Visit_type & Classification of visitor according to group etc. & $\begin{array}{l}\text { "solitary", "pair", "family group", "friend group", } \\
\text { "club group", "school group", "tourist group" [40] }\end{array}$ \\
\hline Visit_motivation_type & The purpose of the visit. & “education”, "enjoyment", “study,” \\
\hline Visit_frequency_level & $\begin{array}{l}\text { How often the visitor has visited the } \\
\text { gallery/museum. }\end{array}$ & $\begin{array}{l}\text { "daily", "weekly", "monthly", "annually", "first } \\
\text { visit," }\end{array}$ \\
\hline Visit_duration_level & Average time visitor spends in gallery/museum. & "brief", "medium-term", "long term," \\
\hline Skills & Attributes of visitor relevant to visits and topic. & "IT", "interface", "language", "reading," \\
\hline Skills_linguistic_type & $\begin{array}{l}\text { The visitor's language of interaction (e.g. } \\
\text { English). }\end{array}$ & $\begin{array}{l}\text { "first language only", "second language", } \\
\text { "multilingual," }\end{array}$ \\
\hline Skills_reading_level & The visitor's ability to read in the 'first language'. & "beginner", "intermediate", "advanced," \\
\hline Skills_IT_level & Visitor's general IT proficiency. & "novice", "intermediate", “expert” [45]. \\
\hline Skills_interface_level & $\begin{array}{l}\text { Visitor's level of experience of using type of } \\
\text { interface. }\end{array}$ & "novice", "intermediate", "expert”[45]. \\
\hline Behaviour & How the visitor behaves in relation to a visit. & $\begin{array}{l}\text { "personality", "learning”, "behaviour", } \\
\text { "movement," }\end{array}$ \\
\hline Behaviour_personality_type & $\begin{array}{l}\text { Personal traits of the visitor (e.g. OCEAN or } \\
\text { CANOE model. }\end{array}$ & $\begin{array}{l}\text { “open-ness to experience", "conscientiousness", } \\
\text { "extraversion", "agreeableness", "neuroticism" } \\
{[37] .}\end{array}$ \\
\hline
\end{tabular}




\begin{tabular}{|c|c|c|}
\hline Behaviour_learning_type & How the visitor learns best (e.g. VARK model). & "visual", "auditory", "reading", "kinaesthetic" [46]. \\
\hline Behaviour_attitude_type & $\begin{array}{l}\text { How the visitor behaves on a visit in relation to the } \\
\text { exhibits. }\end{array}$ & "busy", "greedy", "selective" [47]. \\
\hline Behaviour_movement_type & $\begin{array}{l}\text { How the visitor moves around exhibitions and } \\
\text { exhibits }\end{array}$ & “ant”, “fish”, "grasshopper”, "butterfly” [43]. \\
\hline Interest & What the visitor is most interested in. & $\begin{array}{l}\text { "painting", "sculpture, "history, "science", } \\
\text { "technology", "geography", "anthropology," }\end{array}$ \\
\hline Interest_knowledge_level & The visitor's prior knowledge/experience of topic. & “superficial”, “developing”, “in-depth” [48]. \\
\hline Interest_gallery_type & Visitor's topic of interest in art gallery. & $\begin{array}{l}\text { "Renaissance", "Neoclassicism, "Romanticism", } \\
\text { "Modern", "Contemporary," }\end{array}$ \\
\hline Interest_museum_type & Visitor's topic of interest in museum. & $\begin{array}{l}\text { "Prehistoric", "ancient civilizations", "Ancient } \\
\text { Greece", "Middle Ages", "Industrial Revolution", } \\
\text { "America and the New World" }\end{array}$ \\
\hline Interest_exhibit_level & Visitor's interest in topic area. & $\begin{array}{l}\text { "low", "moderately low", "moderate", "moderately } \\
\text { high", "high," }\end{array}$ \\
\hline Preference & The type of establishment most visited by visitor. & $\begin{array}{l}\text { "art gallery", "museum”, "virtual gallery", "virtual } \\
\text { museum". }\end{array}$ \\
\hline Preference_exhibition_size & The scale of the exhibition preferred by visitor. & "small, "medium", "large," \\
\hline Preference_room_layout & $\begin{array}{l}\text { The type of exhibition/room layout the visitor } \\
\text { prefers. }\end{array}$ & "linear, "open plan”, "free-flowing” [19]. \\
\hline Context & The visitor's current situation. & "working”, "socialising", "studying", "leisure," \\
\hline Time & The date/time associated with the visitor's session. & "minute", "hour", "date," \\
\hline Location & The visitor's physical location. & "IP address", "country", “city" \\
\hline Activity & What the visitor is doing. & "virtual tour", "fact-finding", "browsing," \\
\hline
\end{tabular}

\section{APPLYING ONTOLOGY ENGINEERING}

The first stage in applying the $\mathrm{OE}$ approach to a personalized gallery or museum application is constructing a visitor profile ontology as shown in Table I.

The first step, is to define the classes by providing them with unique identifier names ('Class_name'). The next step is to ensure that the ontology is understandable by including a narrative of the class ('Class_description'). Finally, a number of possible attributes of the class ('Example_values') can be listed. Although in practice these would not be exclusive, as other class names and attributes can be added dynamically as the ontology adapted to its requirements through capturing additional implicit information by monitoring the visitor's behavior and actions and as its ability to refine the personalized profile increases. This ability to combine static explicit information with dynamic implicit information makes profiling such a powerful tool for modelling visitor preferences and behavior. The greater the extent of personalization, the more enhanced will be the visitor experience and the greater his or her satisfaction with the virtual visit.

The next stage of the application is to construct the ontological structure as shown in Fig. 2, linking the key classes in the ontology [49].

This follows a top-down design approach, where 'high level' or general concepts relating to the visitor are captured (e.g. "education", "impairments" etc.). The main class Visitor represents any user of a virtual gallery or museum and the VisitorProfile is the central class within the ontology. It links semantically to five key profile classes and decomposes into more detailed or specialized attributes or properties (e.g. Skills, Behaviour, Interest and Preference).
These top-level class attributes are further broken down into five top-level profile classes: VisitProfile, SkillsProfile, BehaviourProfile, InterestProfile and PreferenceProfile. Each of these profiles can be decomposed further into a series of second level classes based on their type, showing a property of the class or level, and indicating a measure (e.g. skills_reading_level and behaviour_personality_type). This ontology enables a dynamic profile of the visitor to be stored and maintained. For instance, the visitor's virtual location can be updated continuously as he or she moves about the gallery or museum, and a pattern of movement can be applied to the profile. Also the visitor's reading and linguistic levels can be updated dynamically when an improvement occurs or when a change is noted in the Skills_linguistic_level and Skills_reading_level in the SkillsProfile. The top-level classes function as follows:

- SkillsProfile relates to the visitor's abilities in relation to his or her experience of the virtual visit (e.g. Skills_linguistic_level);

- BehaviourProfile holds useful facts about the way in which he or she approaches the virtual visit (e.g. Behaviour_personality_type);

- InterestProfile holds facts about the visitor's topic(s) of interest within a virtual gallery or museum (e.g. Interest_knowledge_level);

- PreferenceProfile captures the visitor's preferred exhibition layout (e.g. Preference_exhibiton_type).

There is a hierarchical relationship between the top and second level classes and the object and data properties for the top-level classes. For instance, each 'Context' hasTime, each 'Activity' hasLocation. This enables the ontology to keep a record of the visitor's activities and the context within which they occur, allowing the ontology to be refined. Also the ontology can be automated semantically, e.g. by using the 
Web Ontology Language OWL, and can be edited using the Protégé editor to maintain its hierarchical structure. Although beyond the scope of this paper, this offers some advantages:

- It allows reasoning about the ontology to take place, for instance updating the profiles or automatically classifying instances in classes;

- It includes automatic checking for the consistency of the ontology by detecting anomalies or unintended relationships between classes;

- There are different 'levels' of OWL that can be tailored to different virtual gallery or museum applications. OWL Lite provides a basic classification hierarchy, Owl DL (Description Logic) offers greater computability and reasoning support and OWL Full allows greater semantic and syntactic expressiveness without the same degree of computability [21].

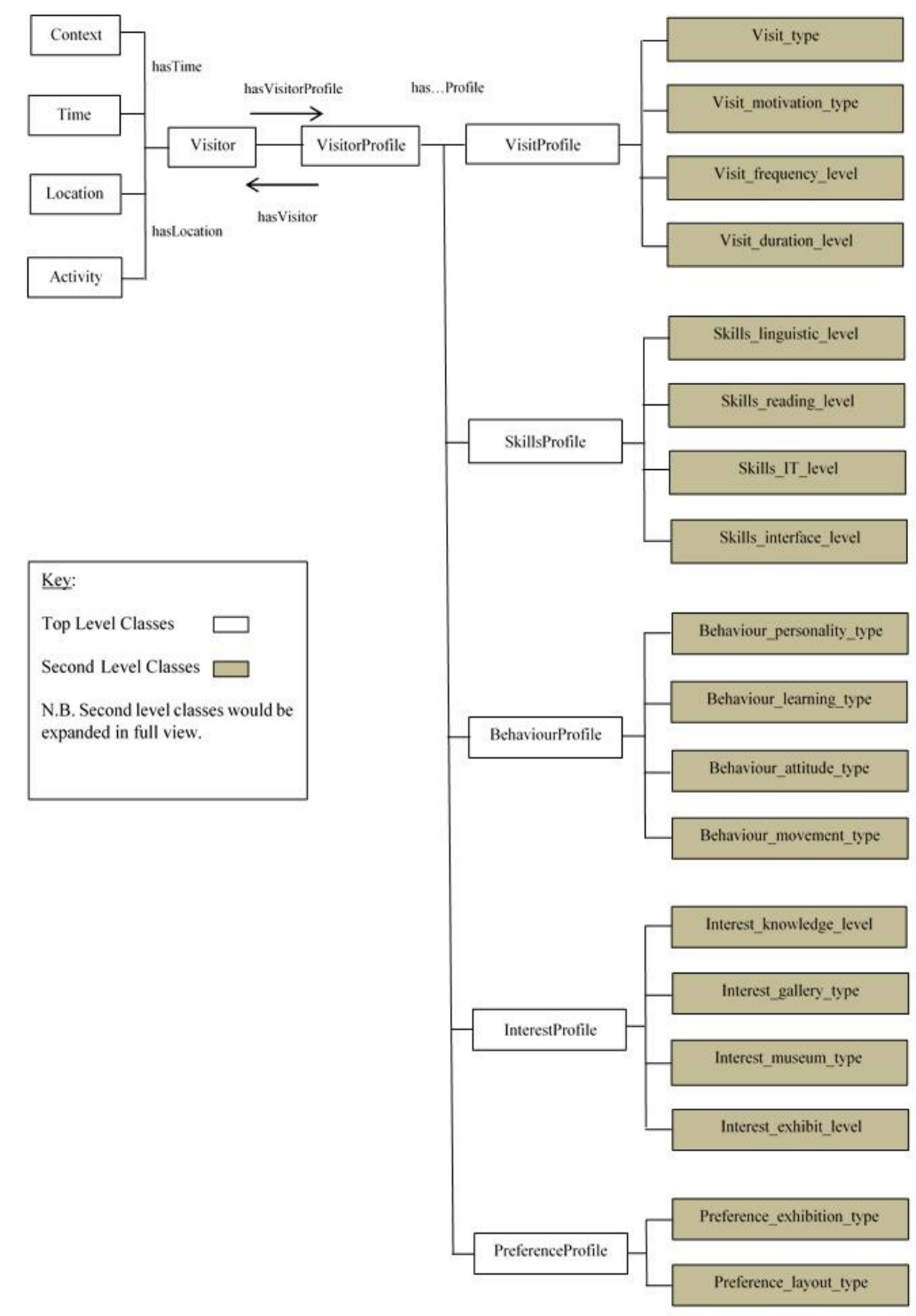

Fig. 2. Example of visitor profile ontology showing the hierarchical structure (Based on Skillen et al. [49]).

\section{CONCLUSIONS}

It is the mission of a cultural heritage site to entertain as well as to educate its visitors. This applies no less to a virtual gallery or museum than to a real one. The experience of visitors to virtual galleries and museums can be enriched by a process of personalization based on an understanding of their visitor profile that enables content to be adapted according to their interests, preferences, skills and habits. This allows a dialogue to be established that can be likened to 'talking with the visitor' rather than 'talking to the visitor' as in a conventional guided tour. The research shows that there is potential in the OE approach to establish strong hierarchical ontologies that describe well the visitors' profiles and to provide a high degree of personalization. Future developments in the field could naturally embrace gamification of the explicit part of the static visitor profile (e.g. reward-based play) and the inclusion of artificial intelligence (AI) agents to gather implicit data in order to adapt the dynamic part of the visitor profile as the visitor progresses through the virtual exhibition.

\section{REFERENCES}

[1] O. Bimber and R. Raskar, Spatial Augmented Reality: Merging Real and Virtual Worlds, Natick, ch. 1, 2005.

[2] A. Antoniou and G. Lepouras, "Modeling visitors' profiles: A study to investigate adaptation aspects for museum learning technologies," 
ACM Journal on Computing and Cultural Heritage. vol. 3, no. 2. 2010.

[3] A. Antoniou, G. Lepouras, I. Lykourentzou, and Y. Naudet, "Connecting physical space, human personalities, and social networks: the experimedia Blue project," in Proc. the International Biennial Conference Hybrid City, Subtle Revolutions, University Research Institute of Applied Communication, Athens, May 2013, pp. 197-200.

[4] M. C. Beardsley, "The concept of the art museum," The Idea of the Museum: Philosophical, Artistic, and Political Questions, Lewiston, pp. 79-81, 1998.

[5] M. B. Carmo and A. P. Claudio, "3D virtual exhibitions," DESIDOC: Journal of Library \& Information Technology, vol. 33, no. 3, pp. 222-235, May 2013.

[6] S.-C. Chou, W. T. Hsieh, F. L. Gandon, and N. M. Saleh, "Semantic web technologies for context-aware museum tour guide applications," in Proc. International Conference on Advanced Information Networking and Applications, vol. 2, IEEE, 2005.

[7] D. Petrelli, E. Not, and M. Zancarono, "Getting engaged and getting tired: What is in a museum experience?" in Proc. the User Modelling Workshop on Attitude, Personality and Emotions in User-Adapted Interaction, Canada, pp. 23-24, June 1999.

[8] Virtual Free Sites. (May 2016). Virtual tours of museums, exhibits and points of special interest. [Online]. Available: http://www.virtualfreesites.com/museums.html

[9] Y. Naudet, I. Lykourentzou, E. Tobias, A. Antoniou, J. Rompa, and G. Lepouras, "Gaming and cognitive profiles for recommendations in museums," in Proc. the Social Media Adaptation and Personalization (SMAP) Workshop, Bayonne, France, pp. 67-72, December 2013.

[10] Smithsonian Natural History Museum in Washington. (May 2016). Panoramic virtual tour. [Online]. Available: http://naturalhistory.si.edu/panoramas/

[11] Louvre Museum. (May 2016). Online tours. [Online]. Available: http://www.louvre.fr/en/visites-en-ligne

[12] Oxford University. Oxford University Museum of Natural History. virtual tour. [Online]. Available: http://www.chem.ox.ac.uk/oxfordtour/universitymuseum/

[13] F-Museum Virtual Museum. [Online]. Available: http://europeanvirtualmuseum.net/

[14] Rijksmuseum, Amsterdam. Virtual tour. [Online]. Available: www.rijksmuseum.nl

[15] T. R. Gruber, "toward principles for the design of ontologies used for knowledge sharing," International Journal Human-Computer Studies, vol. 43, no. 5-6. pp. 907-928, 1995.

[16] N. Guarino, "formal ontology, conceptual analysis and knowledge representation," International Journal of Human-Computer Studies, vol. 43, no. 5-6. pp. 625-640, 1995.

[17] R. Neches, R. E. Fikes, T. Finin, T. Gruber, R. Patil, T. Senator, and W. R. Swartout, "Enabling technology for knowledge sharing," $A I$ Magazine. vol. 12, no. 3, pp. 16-36, 1991.

[18] R. Studer, V. R. Benjamins, and D. Fensel, "Knowledge engineering. Principles and methods," Data \& Knowledge Engineering, vol. 25, no. 1-2, pp. 161-197, 1998.

[19] N. Guarino, "Formal ontology in information systems," in Proc. the First International Conference (FOIS'98), vol. 46, Amsterdam, pp. 3-15, June 6-8, 1998.

[20] J. Hendler, "Agents and the semantic web," IEEE Intelligent Systems, vol. 2, pp. 30-37, March-April 2001.

[21] O. Signore, "The semantic web and cultural heritage: Ontologies and technologies help in accessing museum information," in Proc. IT for the Virtual Museum, Sonderburg, Denmark, Dec. 6-7, 2006.

[22] A. V. Renssen, Gellish: A Generic Extensible Ontological Language, Holland: Delft University Press, 2005.

[23] A. Sheth and C. Ramakrishnan, "Semantic Web technology in action: Ontology driven information systems for search, integration and analysis," IEEE Data Engineering Bulletin, Special Issue on Making the Semantic Web Real, December 2003.

[24] DigiCULT, Themed Issue 3: Towards a Semantic Web for Heritage Resources. May 2003.

[25] Dublin Core Metadata Initiative. [Online]. Available: http://dublincore.org/documents/dces/

[26] CIDOC Conceptual Reference Model (CRM). [Online]. Available: http://www.cidoc-crm.org/

[27] FOAF Project. [Online]. Available: http://www.foaf-project.org/

[28] A. Bernaras, I. Laresgoiti, and J. Corera, "Building and reusing ontologies for electrical network applications," in Proc. the European Conference on Artificial Intelligence (ECAI'96), Budapest, Hungary, pp. 298-302, 1996.
[29] B. Swartout, P. Ramesh, K. Knight, and T. Russ, "Toward distributed use of large-scale ontologies," AAAI Symposium on Ontological Engineering, Stanford, California, 1997.

[30] M. Fernandez, A. Gomez-Perez, and N. Juristo "Methontology: From ontological art towards ontological engineering," AAAI Technical Report SS-97-06, AAAI Press, Menlo Park, California: USA, pp. 33-40, 1997.

[31] M. Fernández-López, "Overview of methodologies for building ontologies," in Proc. IJCAI99 Workshop on Ontologies and Problem-Solving Methods: Lessons Learned and Future Trends, Stockholm, Sweden, 1999.

[32] Y. Wang, L. Aroyo, N. Stash, and L. Rutledge, "interactive user modelling for personalized access to museum collections: The rijksmuseum case study," in Proc. the 11th User Modelling Conference, Corfu, Greece, June 2007.

[33] S. Gauch, M. Speratta, A. Chandramouli, and A. Micarelli, "User profiles for personalised information access," in Proc. the Adaptive Web, Berlin, Germany: Springer, pp. 54-89, 2007.

[34] M. Pechenizkiy and T. Calders, "A framework for guiding the museum tours personalization," in Proc. the Workshop on Personalised Access to Cultural Heritage (PATCH07) in the $11^{\text {th }}$ International Conference on User Modeling, Corfu, Greece, pp. 11-28, 2007.

[35] L. Aroyo, N. Stash, Y. Wang, P. Gorgels, and L. Rutledge, CHIP Demonstrator: Semantics-Driven Recommendations and Museum Tour Generation, Berlin, Heidelberg: Springer, pp. 879-886, 2007.

[36] P. Waddington, "Dying for information: An investigation of information overload in the UK and world-wide," London: Reuters Business Information, 1996.

[37] S. Schiaffino and A. Analía, "Intelligent user profiling," Artificial Intelligence an International Perspective, Heidelberg, Berlin: Springer, pp. 193-216, 2009

[38] L. Najbrt and J. Kapounova, "Categorization of museum visitors as part of system for personalized museum tour," International Journal of Information and Communication Technologies in Education (ICTE), vol. 3, no. 1. pp. 17-27, 2014.

[39] D. Dean, "Museum exhibition theory and practice" London: Routledge, 1994.

[40] E. Hooper-Greenhill, Museums and Their Visitors, London: Routledge, 2013.

[41] B. A. McCarthy and D. McCarthy, Teaching around the 4MAT Cycle: Designing Instruction for Diverse Learners with Diverse Learning Styles, Thousand Oaks, California: Corwin Press, 2006.

[42] A. Antoniou, I. Lykourentzou, J. Rompa, E. Tobias, G. Lepouras, C. Vassilakis, and Y. Naudet, "User profiling: Towards a Facebook game that reveals cognitive style," Games and Learning Alliance, Springer International Publishing, pp. 349-353, 2013.

[43] E. Verón and M. Levasseur, "Ethnographie de l'exposition: l'espace, le corps et le sens," Bibliothèque Publique d'Information, Centre Georges Pompidou, Paris, 1998.

[44] J. P. Bowen and S. Filippini-Fantoni, "Personalization and the web from a museum perspective," International Conference on Museums and the Web 2004, Arlington, Virginia, USA, pp. 63-78. 2004.

[45] F. Paternò and C. Mancini, "Effective levels of adaptation to different types of users in interactive museum systems," Journal of the American Society for Information Science, vol. 51, no.1. pp. 5-13, 2000.

[46] D. E. Johnson and J. S. Potts, "Public education: Seeking to engender marine stewardship at the UK National Maritime Museum," Ocean Yearbook Online, vol. 20, no. 1, pp. 623-642, 2006.

[47] F. Bohnert and F. Zukerman, "Using viewing time for theme prediction in cultural heritage spaces," $A I$ 2007: Advances in Artificial Intelligence, Berlin: Springer, pp. 367-376, 2007.

[48] D. Qian, "Assessing the roles of depth and breadth of vocabulary knowledge in reading comprehension," Canadian Modern Language Review, vol. 56, no. 2, pp. 282-308, 1999.

[49] K. L. Skillen, L. Chen, C. D. Nugent, M. P. Donnelly, W. Burns, and I. Solheim, "Ontological user profile modeling for context-aware application personalization," Ubiquitous Computing and Ambient Intelligence, Berlin: Springer, pp. 261-268, 2012.

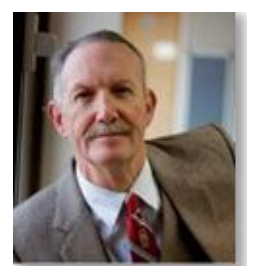

W. Alan Eardley was born in Stoke-on-Trent, U.K in 1949. He obtained a B.A. in business studies in 1984 and a master's degree in computer science from Aston University in the U.K. in 1989. His PhD from Southampton University in the U.K., was awarded in 2001. Alan is professor of enterprise computing in the School of Computing at Staffordshire University in the U.K. and is an adjunct professor at Asia Pacific 
University of Technology and Innovation in Kuala Lumpur. Professor Eardley researches into and teaches knowledge management and IT strategy, publishes widely on both subjects and supervises $\mathrm{PhD}$ students from all over the world.

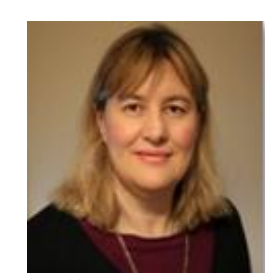

Denise E. Ashe was born in Stroud, Gloucestershire in the U.K. She has a B.Sc. in computing from Wolverhampton University in the U.K. awarded in 1996. Denise has a master's degree with distinction in computer science from Staffordshire University in the U.K. Denise was awarded the Faculty Prize for her masters dissertation. She is now a PhD student in the Faculty of Arts and Creative Technologies at Staffordshire University and is studying the potential of gamification and semiotics for optimizing user profiling and personalization of gallery and museum virtual interfaces.

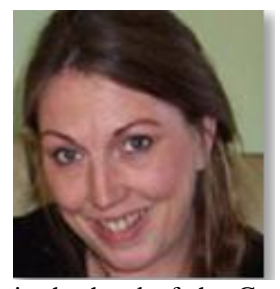

Bobbie Fletcher gained a B.Eng. with honors in mechanical engineering from Plymouth University in the U.K. in 1990 and has a PhD in mathematical modelling and simulation from the University of Plymouth. Dr. Fletcher has undertaken extensive research into reward in games, reward and demographics in games, as well as immersion and audience interaction with augmented reality. She

is the head of the Games Technology Group in the Faculty of Arts and Creative Technologies at Staffordshire University in the U.K. and Applied Research Centre Director for the Centre for Media, Arts and Technology. 